\title{
Inelastic deformation demands of regular steel frames subjected to pulse-like near-fault ground shakings
}

\author{
Navid Siahpolo ${ }^{1} \cdot$ Mohsen Gerami $^{2} \cdot$ Reza Vahdani $^{2}$
}

Received: 17 September 2015/Accepted: 1 August 2016/Published online: 12 August 2016

(C) The Author(s) 2016. This article is published with open access at Springerlink.com

\begin{abstract}
Evaluating the capability of elastic Load Patterns (LPs) including seismic codes and modified LPs such as Method of Modal Combination (MMC) and Upper Bound Pushover Analysis (UBPA) in estimating inelastic demands of non deteriorating steel moment frames is the main objective of this study. The Static Nonlinear Procedure (NSP) is implemented and the results of NSP are compared with Nonlinear Time History Analysis (NTHA). The focus is on the effects of near-fault pulselike ground motions. The primary demands of interest are the maximum floor displacement, the maximum story drift angle over the height, the maximum global ductility, the maximum inter-story ductility and the capacity curves. Five types of LPs are selected and the inelastic demands are calculated under four levels of inter-story target ductility $\left(\mu_{\mathrm{t}}\right)$ using OpenSees software. The results show that the increase in $\mu_{\mathrm{t}}$ coincides with the migration of the peak demands over the height from the top to the bottom stories. Therefore, all LPs estimate the story lateral displacement accurately at the lower stories. The results are almost independent of the number of stories. While, the inter-story drift angle (IDR) obtained from MMC method has the most appropriate accuracy among the other LPs. Although, the
\end{abstract}

Navid Siahpolo

n_siahpolo@yahoo.com

Mohsen Gerami

mgerami@semnan.ac.ir

Reza Vahdani

reza.vahdani2001@gmail.com

1 Department of Civil Engineering, ACECR Institute for Higher Education, Khouzestan Branch, Ahwaz, Iran

2 Department of Earthquake Engineering, University of Semnan, Semnan, Iran accuracy of this method decreases with increasing $\mu_{\mathrm{t}}$ so that with increasing number of stories, IDR is smaller or greater than the values resulted from NTHA depending on the position of captured results. In addition, increasing $\mu_{\mathrm{t}}$ decreases the accuracy of all LPs in determination of critical story position. In this case, the MMC method has the best coincidence with distribution of inter-story ductility over the height.

Keywords Pushover method - Load pattern - Target ductility $\cdot$ Inelastic demand $\cdot$ Near-fault ground shakings

\section{Introduction}

Using elastic analysis is considered in many seismic codes due to the simplicity and modeling assumptions. But, the experience of previous earthquakes confirms the entry of a structure to inelastic region. Thus, linear analysis cannot provide an accurate picture of inelastic demands. Although, the Nonlinear Dynamic Procedures (NDP) can provide a precise estimation of the structural responses, but the complexities of modeling, initial assumptions and earthquake content can affect the results of this method adversely. Therefore, several research efforts have focused on a simplified method of nonlinear analysis, which calculate envelope of inelastic demands of structure using simulation of structural behavior against an incremental monotonic loading. This method is known as Nonlinear Static Procedures (NSPs) or pushover analysis and it has been entered in different codes including the Iranian code of practice for seismic-resistant design of buildings (Standard 2800-4th edition). This method is also used in Performance-Based-Design. That is why several recent studies have had more focus on developing and promoting 
modified NSPs (conventional and adaptive). Today, Conventional Pushover Analysis (CPA) has been entered in many seismic codes such as ASCE/SEI 41-13 (2013). In conventional form, first a lateral Load Pattern (LP) is selected. In different codes, the LP is usually defined based on the relation of static load distribution over the height, uniform distribution and modal distribution. Under this monotonic LP, the structure is pushed up to reach the target displacement. Then, inelastic demands of structure are recorded and compared with preselected performance criteria. The main deficiency of conventional methods is that the LP remains constant during plastic hinge development. In other words, the effect of nonlinearity on stiffness matrix and corresponding mode shapes on the LPs are neglected. To overcome an aforementioned deficiency, several advanced methods have been proposed such as multi, single and adaptive modal NSPs. In the adaptive NSPs, in each loading step, stiffness matrix is calculated based on elastic and inelastic properties of elements and the LP corresponding to the mode shape of the same step is produced. However, performing adaptive NSPs requires special calculations.

With this introduction, it is clear that in all NSPs, the LP is a key step of analysis. As mentioned before, the pushover methods are classified into two categories. In conventional methods, the load distribution pattern remains constant within the inelastic behavior of the structure. In many cases, it is assumed that the load distribution pattern is calculated based on the first mode response. While using these LPs for the structures affected by contribution of higher modes can lead to inaccurate results. Several studies have been conducted to improve pushover methods and overcome these deficiencies. Among these, Multi-mode pushover method is proposed (Moghadam and Tso 2002; Chopra and Goel 2002). One of common Multi-mode methods is the Modal Pushover Analysis or MPA in which the response of structures is calculated against LPs corresponding to each mode and then, the results of analysis are combined using common modal combination methods. It should be noted that the MPA method is in fact a type of NTHA that is performed on the equivalent SDOFs. In this method, the vibration mode is considered elastic (Chopra and Goel 2002; Chopra et al. 2004). Adaptive LPs are defined in the second category. Since the stiffness matrix changes by entering to inelastic region, the LPs should also be corresponding to these changes. In this case, adaptive LPs are proposed (Gupta and Kunnath 2000; Aydinoğlu 2003; Kalkan and Kunnath 2006). All adaptive methods except that was proposed by Aydinoğlu (2003), cannot consider the interaction between different modal responses which is known as Higher Mode Effects (HMEs). Since the adaptive methods are difficult and may not be used simply by engineers for professional purposes, some researchers are looking for modifying and proposing new LPs that are capable to estimate the global and local demands of structures without the need to use changes of the stiffness matrix (Kalkan and Kunnath 2004; Jan et al. 2004).

It seems that due to complicated behavior of structures under the effect of pulselike near-fault earthquakes, extending different LPs, which are originally based on studies conducted on far-fault earthquakes, are necessary for near-fault earthquakes. The fundamental question is that how different LPs (either proposed in seismic codes or new patterns) can capture the structure demand parameters such as base shear, story displacement, inter-story drift angle, and global, inter-story and local ductility properly. That is why in this research, in addition to evaluate the capabilities of LPs, the authors decided to compare various inelastic demands such as absolute floor story displacement (noted as RD in this paper), inter-story drift angle (IDR), global $\left(\mu_{\mathrm{g}}\right)$ and story $\left(\mu_{\mathrm{s}}\right)$ ductility resulted from conventional NSPs with the results of the NTHA. For the comparison, the mean value of aforementioned responses resulted from NTHA have been considered. To perform NTHA, 20 pulse-like near-fault earthquakes having forward directivity effects and strike-normal component were selected. The characteristics of selected records are provided in Table 1. The main feature of this paper is an analytical study of the capabilities of the various LPs towards values obtained from the NTHA (affected by nearfault earthquakes) in calculating the Engineering Demand Parameters (EDPs) in terms of inter-story ductility considering the effect of higher modes. To scale earthquakes adjusting inter-story demand ductility equal to the predefined target ductility value is used. We have also used the same idea to calculate the target displacement of various LPs to satisfy this criterion. Therefore, it is possible to compare the results of NSP with the average results of the NTHA. Previous studies confirm that the effect of higher modes in near-fault earthquakes affects the global, interstory and local responses (either elastic or inelastic) of structure more than ordinary ground motions (Gerami and Abdollahzadeh 2015).

\section{An introduction to pushover analysis with elastic load patterns (conventional and modified)}

Since the results of pushover analysis severely depend on the shape of the distributed LP over the height, so it is essential to use different LPs which are obtained from different assumptions. In this paper, we have used five load distribution patterns. Three LPs are taken from ASCE/SEI 41-13 (2013) denoted as LP1, LP2 and LP3. In the first pattern, we used the monotonic distribution method of strength corresponding to structure mass. For second 
Table 1 Characteristics of near-fault earthquakes (NF)

\begin{tabular}{|c|c|c|c|c|c|c|}
\hline Record no. & Earthquake name & Station name & $\mathrm{PGA}^{\mathrm{a}}(\mathrm{g})$ & $\mathrm{Mw}^{\mathrm{b}}$ & $R^{\mathrm{c}}(\mathrm{km})$ & $T_{\mathrm{P}}^{\mathrm{d}}(\mathrm{s})$ \\
\hline 1 & Imperial Valley-06 (1979) & El Centro Array \#4 & 0.61 & 6.53 & 7.05 & 4.61 \\
\hline 2 & Northridge-01 (1994) & Newhall - Fire Sta & 0.18 & 6.69 & 5.92 & 1.03 \\
\hline 3 & Northridge-01 (1994) & Newhall - W Pico Canyon Rd. & 0.33 & 6.69 & 5.48 & 2.40 \\
\hline 4 & Northridge-01 (1994) & Rinaldi Receiving Sta & 0.08 & 6.69 & 6.50 & 1.23 \\
\hline 5 & Northridge-01(1994) & Sylmar - Converter Sta East & 0.58 & 6.69 & 5.19 & 3.52 \\
\hline 6 & Kobe, Japan (1995) & KJMA & 1.05 & 6.90 & 0.96 & 0.95 \\
\hline 7 & Kobe, Japan (1995) & Takarazuka & 0.94 & 6.90 & 0.27 & 1.42 \\
\hline 8 & Landers (1992) & Yermo Fire Station & 0.10 & 7.28 & 23.62 & 7.50 \\
\hline 9 & Imperial Valley-06 (1979) & El Centro Array \#6 & 0.65 & 6.53 & 1.35 & 3.83 \\
\hline 10 & Northridge-01 (1994) & Jensen Filter Plant & 0.12 & 6.69 & 5.43 & 3.52 \\
\hline 11 & Imperial Valley-06 (1979) & EC County Center FF & 0.32 & 6.53 & 7.31 & 4.51 \\
\hline 12 & Imperial Valley-06 (1979) & EC Meloland Overpass FF & 0.44 & 6.53 & 0.07 & 3.34 \\
\hline 13 & Morgan Hill (1984) & Coyote Lake Dam (SW Abut) & 0.23 & 6.19 & 0.53 & 0.95 \\
\hline 14 & Loma Prieta (1989) & Gilroy - Gavilan Coll. & 0.25 & 6.93 & 9.96 & 1.79 \\
\hline 15 & Loma Prieta (1989) & LGPC & 0.84 & 6.93 & 3.88 & 4.39 \\
\hline 16 & Northridge (1994) & Westmoreland & 0.40 & 6.70 & 29.00 & 0.30 \\
\hline 17 & Northridge-01 (1994) & Jensen Filter Plant Generator & 0.12 & 6.69 & 5.43 & 3.52 \\
\hline 18 & Northridge-01 (1994) & Sylmar - Converter Sta & 0.65 & 6.69 & 5.35 & 3.47 \\
\hline 19 & Northridge-01 (1994) & Sylmar - Olive View Med FF & 0.45 & 6.69 & 5.30 & 3.10 \\
\hline 20 & Kocaeli, Turkey (1999) & Gebze & 0.30 & 7.51 & 10.92 & 5.78 \\
\hline
\end{tabular}

${ }^{a}$ Peak ground acceleration

b Moment magnitude

${ }^{c}$ Closest distance from the recording site to the ruptured area

${ }^{d}$ Predominant period (Kramer 1996)

pattern, initially, all models are analyzed by dynamic spectrum analysis (using mean acceleration elastic spectrum resulted from 20 near-fault earthquakes). Then, distributed strength of oscillating modes, with their total effective modal mass more than $90 \%$ of the structure total mass, is combined in each story by SRSS method. In the third category, LP3, is a distributed load over the height corresponding to the Eq. 1. The LP3 is also proposed Standard No.2800-4th (2014).

$F_{x}=V \frac{w_{x} h_{x}^{k}}{\sum_{i=1}^{N} w_{i} h_{i}^{k}}$.

In the above equation, $F_{x}$ is the distributed force of story level $x, h$ is the story height towards the base level and $V$ is the base shear. In addition, $w$ represents the story weight and coefficient $\mathrm{k}$ depends on the structure vibration. For the structure with the vibration period lower than $0.5 \mathrm{~s}$, this coefficient is equal to one and for a vibration period higher than $2.5 \mathrm{~s}$, it is equal to 2. Linear interpolation is used for values between the two values. To apply the effects of higher modes and to improve the elastic load distribution pattern in pushover analysis, the fourth lateral load pattern is selected by the Method of Modal Combination (MMC) proposed by Kalkan and Kunnath (2004). In this method, lateral strength distribution over the height is defined as below:

$F_{j}=\sum \alpha_{n} \Gamma_{n} m \phi_{n} S_{a}\left(\xi_{n}, T_{n}\right)$.

In Eq. $2, \alpha_{n}$ is the correction coefficient, which can be either positive or negative. It means that $\alpha_{n}$ value is +1 or -1 . For an instant, multiply mode 2 and mode 3 with -1 in the case that the mode shape value at the roof should be positive. Also, since in the above equation, $S_{a}\left(\xi_{n}, T_{n}\right)$ is the spectral elastic acceleration resulted from response spectrum of near-fault earthquakes, the earthquake intensity effects are entered in MMC method with this parameter. For example, if just the two first modes are considered, then the Eq. 2 is equal to:

$F_{j}=\alpha_{1} \Gamma_{1} m \phi_{1} S_{a}\left(\xi_{1}, T_{1}\right) \pm \alpha_{2} \Gamma_{2} m \phi_{2} S_{a}\left(\xi_{2}, T_{2}\right)$.

Thus, the MMC method requires performing two separate pushover analysis in which one of the two above loading combination is used. Then, final response of the 
structure is the envelope of two responses obtained from the two above LPs. As the fifth LP (LP5), Upper Bound Pushover Analysis (UBPA) in which proposed by Jan et al. (2004) is considered. In this method, the compound loading pattern obtained from first and second vibration mode is calculated in the form of a unit LP via Eq. 4:

$F_{j}=\omega_{1} m \phi_{1}+\omega_{2} m \phi_{2}\left(q_{2} / q_{1}\right)$.

In Eq. 4 , the term $q_{2} / q_{1}$ is equal to:

$\left|q_{2} / q_{1}\right|=\left|\left(\Gamma_{2} D_{2}\right) /\left(\Gamma_{1} D_{1}\right)\right|$.

In Eq. 5, $\Gamma_{1}$ and $\Gamma_{2}$ are the first and second mode participation factors. In addition, $D_{1}$ and $D_{2}$ are elastic spectral displacement corresponding to the first and second modal period obtained from an elastic spectrum of aforementioned earthquakes, respectively. Figure 1 indicates the acceleration and displacement elastic spectrum of near-field earthquakes used in this research. In addition, values of spectral displacement are marked corresponding to vibration period of first and second mode for each model in Fig. 2.

\section{Method}

\section{Design of buildings}

For all frames of this study, the height of all stories is considered constant and equal to $4 \mathrm{~m}$ and span length equal to $5 \mathrm{~m}$. The special ductility level was selected for twodimensional steel moment frames based on AISC/ANSI 360-10 (2010) section compact classification. To facilitate the introduction of frames, each frame is introduced by the name of $F R N i B j$, where $i$ represents the number of story and $j$ represents the number of spans. For the number of spans, B is considered constant in all frames and equal to 3 . The values of $N$ also include 4, 7, 15, and 20. The frames were loaded in accordance with the Iran standard of loading structures (2014). In all models, dead and live load of all stories were, respectively 3750 and $1250 \mathrm{~kg} / \mathrm{m}$. In addition,

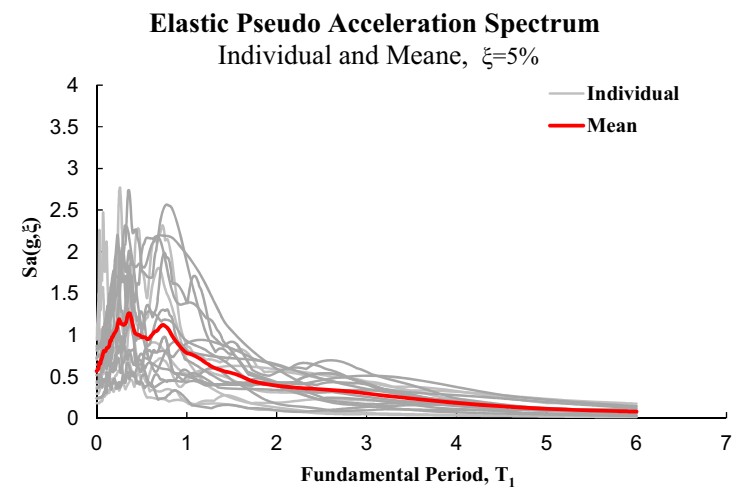

to calculate story mass, dead load plus $20 \%$ of live load has been used. Based on the Iranian seismic codes, the models were designed according to the strength design methodology and were checked for inter-story drift limitation. To design all frames, soil condition type III (according to standard No.2800 Iran) was selected which is almost as same as the soil type D of AISC/SEI 41-13 defined in section 2.4.1.6.1. Furthermore, site hazard level was assumed as a very highrisk category on the basis of standard No.2800 Iran definition (spectrum design base acceleration is $0.35 \mathrm{~g}$ ). All mentioned frames are designed using Etabs2013 software (2013) by means of equivalent static analysis (in some models pseudo dynamic analysis and normalizing the design base shear) in accordance with AISC/ANSI 360-10 (2010) and Iranian National Building Regulations (2008) LRFD method (see Fig. 3). On the basis of steel material specifications by Iranian code, steel type ST37 with yield point of $2400 \mathrm{~kg} / \mathrm{cm}^{2}$ and ultimate stress of $3600 \mathrm{~kg} / \mathrm{cm}^{2}$ was selected for frame design and evaluation. Only the bare steel frame was included in the analysis, i.e., the interaction between the slab and composite beams were not included. The panel zone of the beam-column connections were assumed to be stiff and strong enough to avoid any shear deformation, distortion or yielding under strong earthquakes. The columns were fixed at the ground level. The P- $\Delta$ effects (geometric nonlinearity due to lateral load and deformation) were accounted for in the analysis.

\section{Near-fault pulse like earthquakes}

One of the basic steps in linear and nonlinear time-history analysis is ground motion selection that is often delivered to researchers by record databases such as PEER. What is considered in defining the characteristics of earthquakes, which also distinguishes them from each other, is called strong ground motion parameters. One of the issues, which has been paid special attention to in recent years, is the type of record of earthquake with respect to the epicentre distance to the site. In the case of near-fault earthquake,

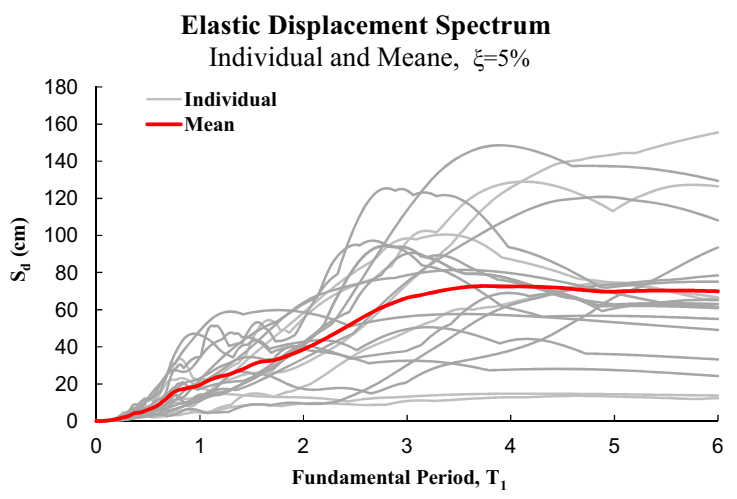

Fig. 1 Elastic acceleration (left) and displacement (right) spectrum of near-field earthquakes 
Displacement Elastic Response Spectra

Near Field Earthquake with Forward Directivity - Strike Normal

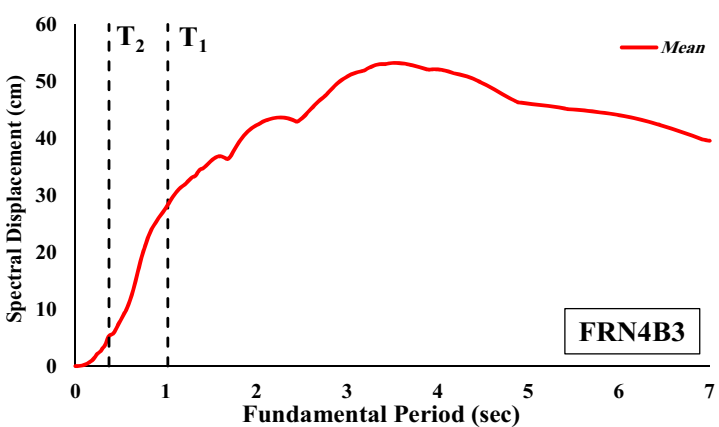

Displacement Elastic Response Spectra Near Field Earthquake with Forward Directivity - Strike Normal

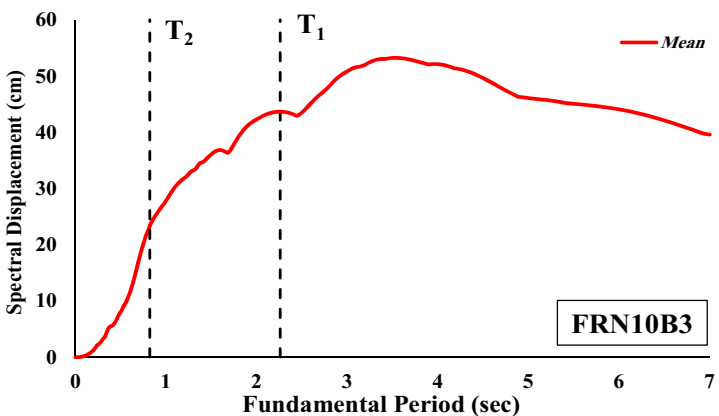

Displacement Elastic Response Spectra

Near Field Earthquake with Forward Directivity - Strike Normal

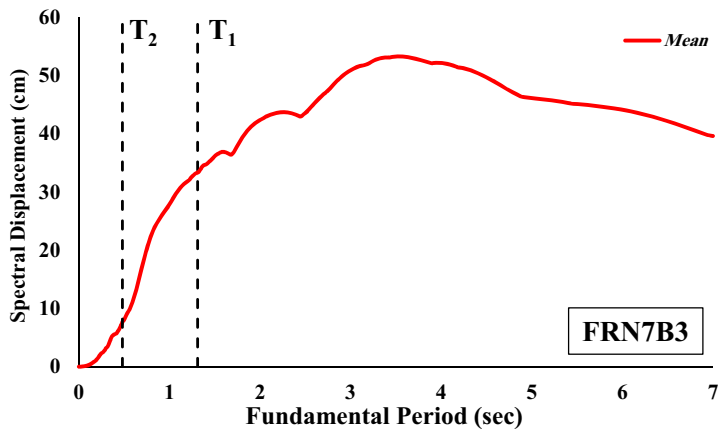

Displacement Elastic Response Spectra

Near Field Earthquake with Forward Directivity - Strike Normal

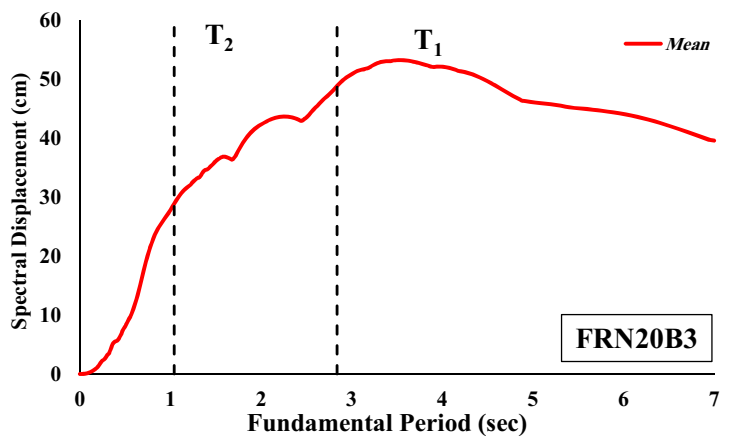

Fig. 2 Spectral displacement of first and second modes of each model (mean value)

\begin{tabular}{|c|l|c|c|c|c|}
\hline Section ID & \multicolumn{1}{|c|}{ Name } & $\mathbf{b}_{\mathbf{f}}$ & $\mathbf{t}_{\mathbf{f}}$ & $\mathbf{h}_{\mathbf{w}}$ & $\mathbf{t}_{\mathbf{w}}$ \\
\hline $\mathrm{C} 1$ & BOX 200X15 & 200 & 15 & 200 & 15 \\
\hline C 2 & BOX 250X15 & 250 & 15 & 250 & 15 \\
\hline C 3 & BOX 300X25 & 300 & 25 & 300 & 25 \\
\hline C4 & BOX 350X30 & 350 & 30 & 350 & 30 \\
\hline C5 & BOX 400X30 & 400 & 30 & 400 & 30 \\
\hline C6 & BOX 450X30 & 450 & 30 & 450 & 30 \\
\hline C7 & BOX 500X40 & 500 & 40 & 500 & 40 \\
\hline C8 & BOX 550X40 & 550 & 40 & 550 & 40 \\
\hline B1 & TW300F150TH15 & 15 & 15 & 300 & 15 \\
\hline B 2 & TW350F150TH15 & 15 & 15 & 350 & 15 \\
\hline B3 & TW400F200TH15 & 200 & 15 & 400 & 15 \\
\hline B4 & TW450F200TH15 & 200 & 15 & 450 & 15 \\
\hline B 5 & TW500F250TH15 & 250 & 20 & 500 & 20 \\
\hline B6 & TW550F250TH20 & 250 & 20 & 550 & 20 \\
\hline
\end{tabular}
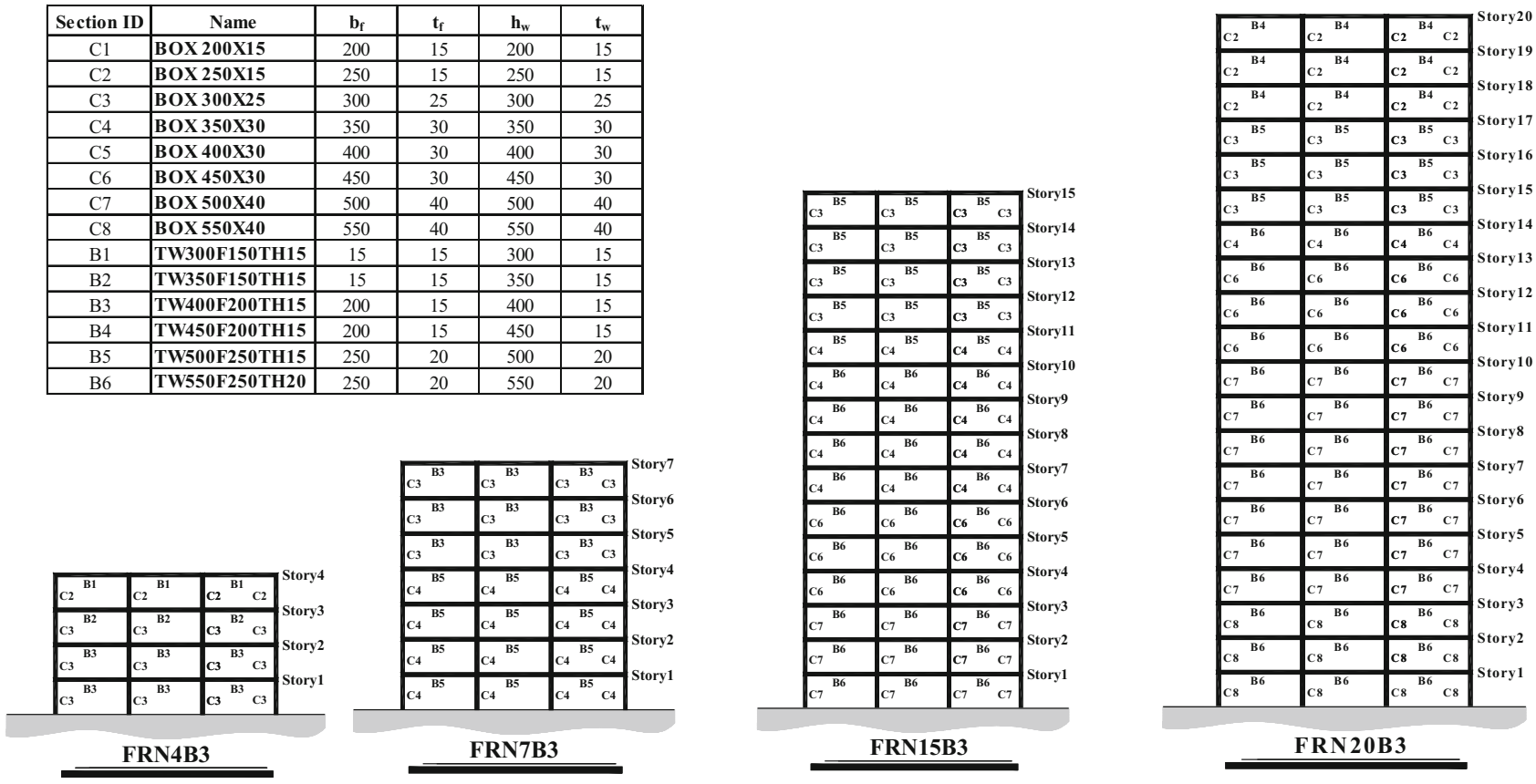

Fig. 3 Details of structural models used in process of pushover analysis and NTHA

significant amounts of earthquake energy will be imposed on the structure in a short time. Therefore, the structure does not have enough time to respond to such vibrations. One important concept in a near-field earthquake is the region with forward directivity effects, i.e., a region in which the fault rupture is towards the site and fault rupture velocity is equal to the shear wave velocity. In this situation, velocity time history and in some cases, acceleration 
time history has an obvious pulse with long period high amplitude motion. Thus, 20 real acceleration time histories are selected from Baker (2007) proposed near field earthquakes. The characteristics of the selected earthquakes are illustrated in Table 1. In Fig. 4 two-acceleration time history of near-fault earthquakes have been depicted.

\section{Nonlinear analysis assumptions}

For the first mode and all modes with cumulative mass participation factor exceeding $90 \%$, Rayleigh equivalent damping was defined as $5 \%$. The strain-stress hysteresis behavior of steel was modelled as a bilinear with a strain hardening ratio of $3 \%$. To perform NTHA, time steps and sub-steps have been considered to be $0.005 \mathrm{~s}$ and 1000 , respectively. In all analysis, P-Delta effect has been included. To model plastic hinge at the end of elements, inelastic force-based element with fiber-distributed plasticity was selected. To do nonlinear dynamic analysis by means of Opensees, each element was divided into ten parts (McKenna et al. 2000). In these parts, the stresses and strains were derived from three points at the top, middle, and bottom corners of the section.

\section{The performance criteria and analysis breakpoint}

There are two reasons for defining performance criterion. The first reason is to determine a target displacement for a given performance level. This value is of great importance in the determination of lateral strength and yield displacement of the structure. There are various methods for defining target displacement, which are outlined as:

- Maximum displacement demand resulted from the NTHA

- Preselected local ductility

- Maximum displacement demand achieved by elastic dynamic force reduced by behavior factor

- Capacity spectrum method (ATC40 1996)

- Method of displacement coefficients [ASCE/SEI 41-13 (2013)]

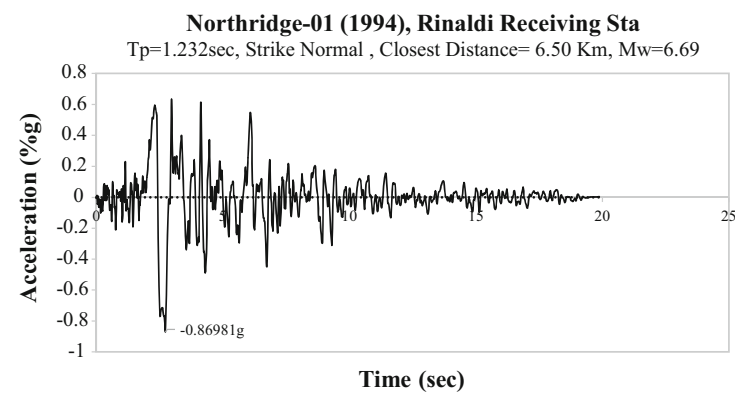

- The spectral dynamic analysis using inelastic response spectrum

Since the main purpose of this study is to evaluate the ability of common LPs in estimating inelastic demands of no deteriorating steel frames and comparing them with NTHA results, both two NSP and NTHA must have the same target demand. In this article, this purpose is achieved by definition of target inter-story ductility. For each of the intended structures and the studied earthquakes (see Table 1), test and trial on the earthquake scale factor was used to conform the inter-story ductility of the structure to the pre-selected inter-story target ductility $(2,3,4$, and 5 in this paper). Moreover, by using trial and error procedure on the target displacement (roof displacement), the inter-story ductility ratio resulting from NSP was set to a pre-defined target value (see Fig. 5a, b).

\section{Results}

\section{Roof displacement}

Peak roof displacement (RD) especially measured at roof level is used as a global damage index in estimating the structural performance that relates to both structural and nonstructural damage of frame structures. However, this parameter is used to prevent collision of two adjacent buildings. To assess the RD distribution profile over the height Fig. 6 is depicted. In this figure, for each model four-displacement profile is portrayed in which the horizontal axis is the maximum $\mathrm{RD}$ and the vertical axis is the story ID. Each sub-figure is drawn corresponding to one of the selected target ductility levels. In these curves, the peak RD resulted from the NTHA is compared with a peak response of the NTHA (mean value of 20 records in red line).

Fig. 6 shows that different LPs provide an appropriate estimation of the roof displacement over the height of the models. This capability depends on the ductility and the number of stories. For instance, for the structure with

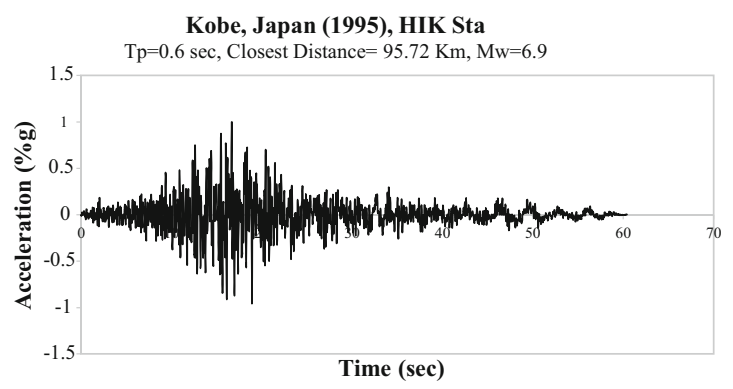

Fig. 4 Time history record of the Northridge earthquake (left) and Kobe (right), strike normal component 


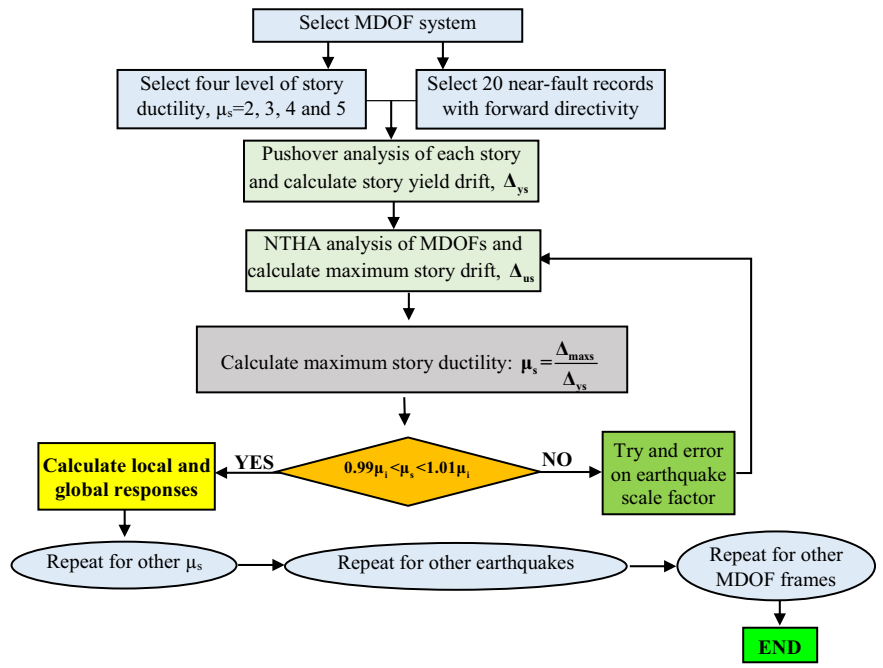

(a)

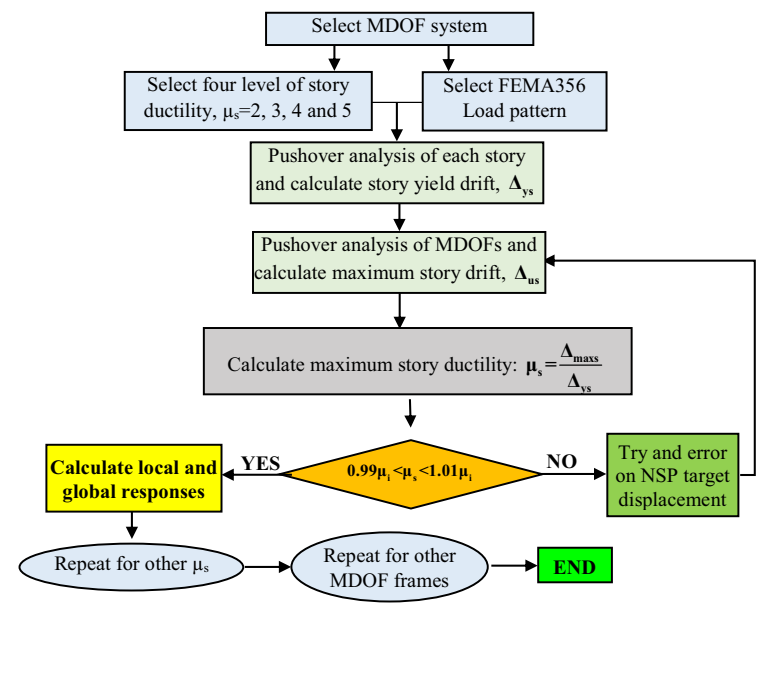

(b)

Fig. 5 Calculation steps of response modification factors. a Non-linear time history analysis (NTHA), b non-linear static procedure (NSP)

$\mu_{\mathrm{s}}=2$ and 3, all LPs estimate the RD more than the NTHA. For a given model, increasing the ductility decreases the RD resulted by NSP. Therefore, the accuracy of LP1 decreases at upper stories. Generally, the qualitative comparison between the results of NSP and NTHA demonstrates that all selected LPs have acceptable ability in estimating RD when the structure is subjected to near fault pulse type earthquakes. Therefore, using the NSP may lead to conservative values for the maximum RD.

\section{Inter-story drift ratio (IDR)}

The maximum inter-story drift ratio over the height (IDR) is relevant for structural damage if the damage is dominated by the maximum story deformation over the height. It is also a measure of damage to nonstructural components, such as partitions, which are sensitive to relative deformations between floors. For P-Delta sensitive structure, IDR is an appropriate demand factor for global collapse assessment when dynamic instability is attained due to the presence of P-Delta effects. Thus, to evaluate the capability of different LPs in predicting IDR, the profile of IDR over the height of each model is provided in Fig. 7.

Qualitative and quantitative evaluation of Fig. 7 indicates that for low-rise models (4-story), in all LPs, the peak IDR profile resulted from NSP is estimated higher than the NTHA except for LP1 at upper stories. By increasing the number of stories, some of LPs have resulted higher values in lower stories; however, these differences are reduced by increasing inter-story ductility level. It means that the accuracy of all LPs strongly depends on the number of stories and ductility value. In the bottom stories, all LPs predict the IDR greater the NTHA. Nevertheless, at the top stories only the LPs in which produced by multi-mode combination rule are capable of predicting the IDR reasonably. Among all five selected PLs, the LP4 (MMC) has the sufficient accuracy (Kalkan and Kunnath 2004). However, increasing target ductility decreases the capability of LP4 at upper floors since due to the effect of P- $\Delta$ the peak IDR migrates from top to bottom stories (see Fig. 8). As a conclusion the result of this section shows that it needs to combine two LPs to capture the peak IDR of buildings under near fault pulse like earthquakes. It is important to select one of the LPs adapted by modal combination methodology (e.g., MMC) and the inelastic behavior level must be considered.

For better understanding of the capability of MMC method (LP4) in estimating IDR, corresponding to different ductility levels (different levels of inelasticity); the error distribution over the height is calculated and depicted in Fig. 9. The error function is defined as follows:

Error $\%=\left(\frac{\mathrm{IDR}_{\mathrm{NTHA}}-\mathrm{IDR}_{\mathrm{NSP}-\mathrm{LP} 4}}{\mathrm{IDR}_{\mathrm{NTHA}}}\right) \times 100$.

Reviewing Fig. 9 reveals that for 4-story model, maximum error is located at the first story independent of ductility value. Also with increasing the ductility level, the error increases. The error calculated for 7 -story structure shows that increasing inelastic behavior transfers the peak error to the top stories. Moreover, for a specific story, increasing ductility may increase the error. For tall models (such as 15 and 20 story models) the error is independent from the ductility. Also the peak value locates at top 

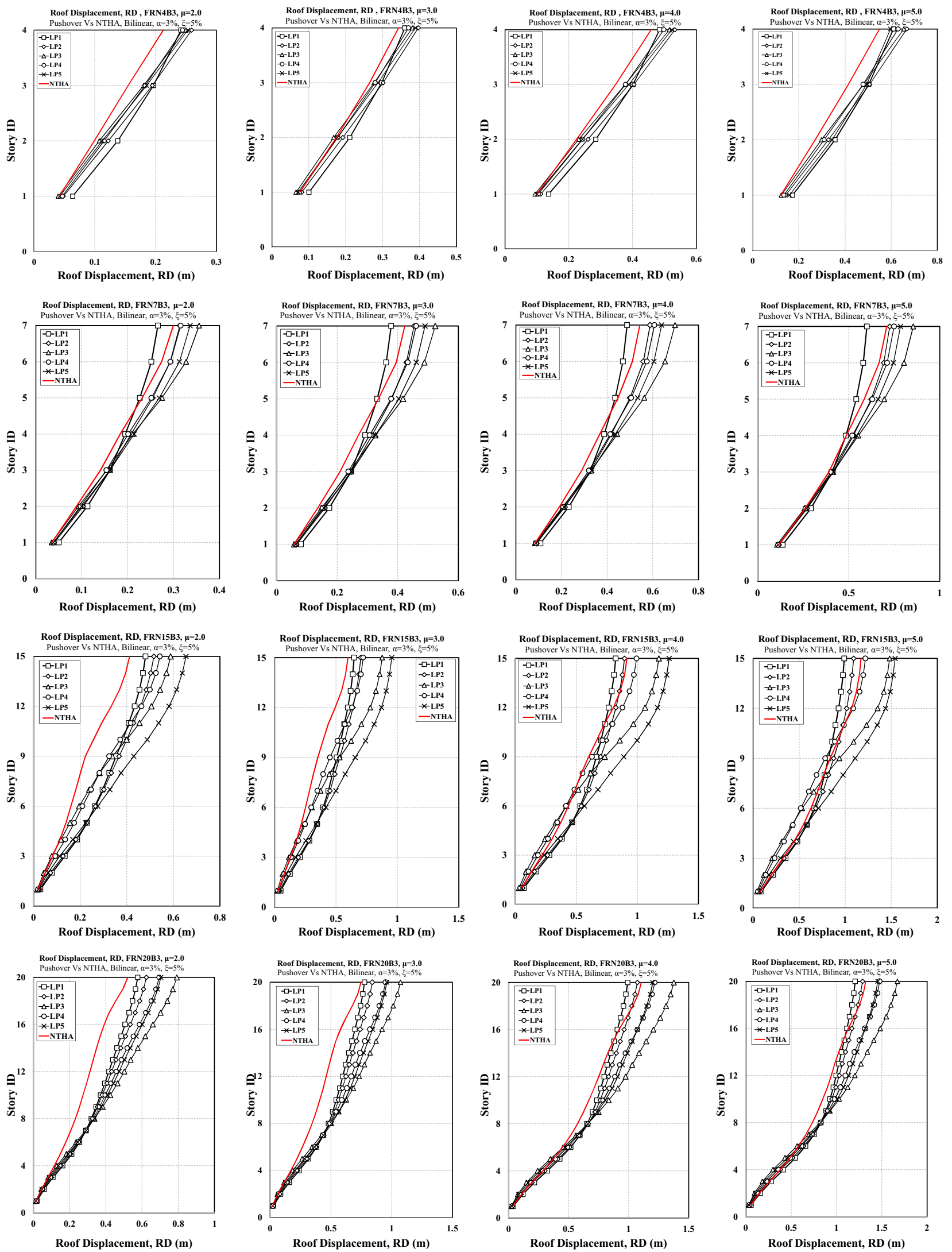

Fig. 6 Distribution of story displacement over the height resulted from different LPs along with the mean value of NTHA, inter-story ductility demand of 2, 3, 4 and 5 

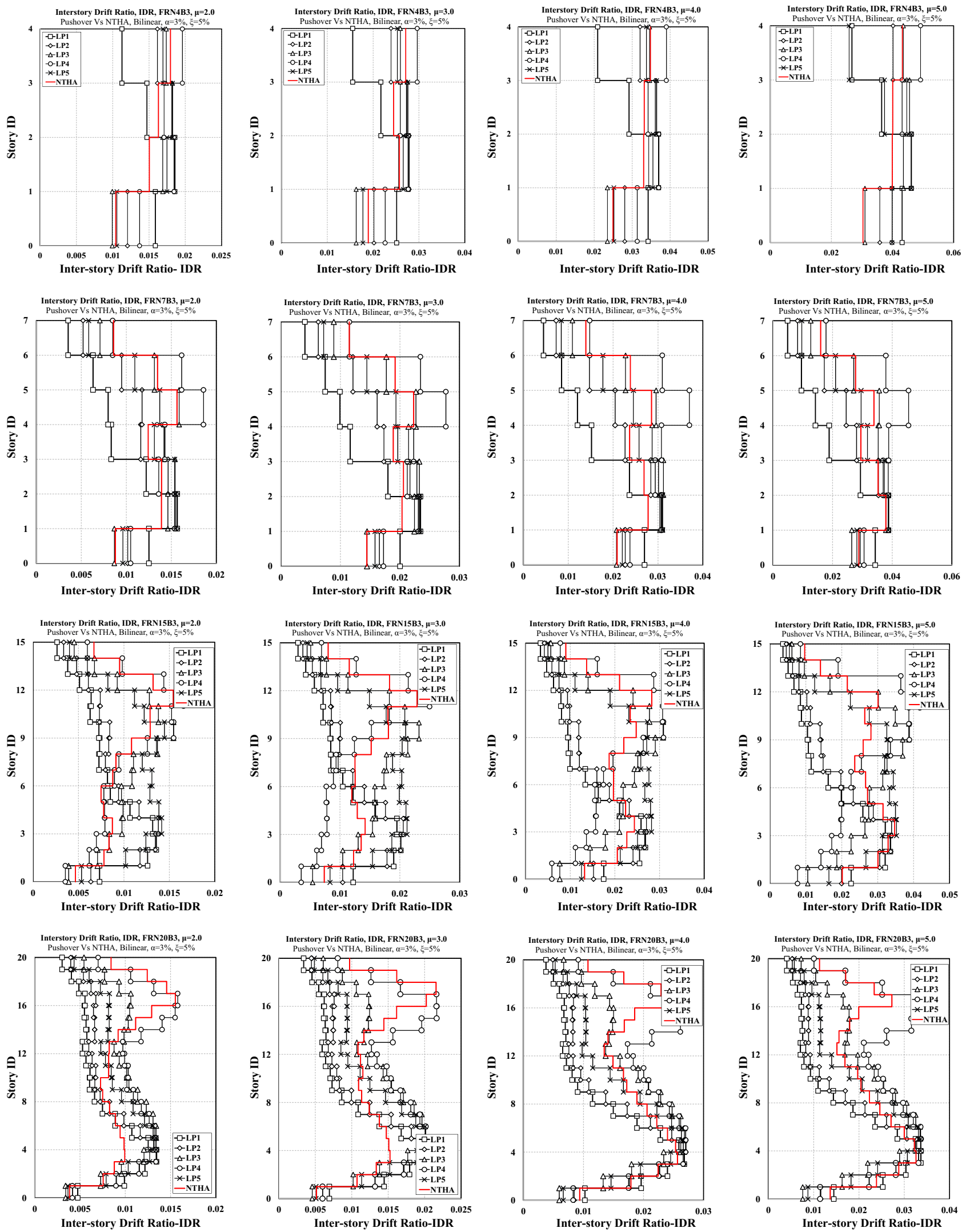

Fig. 7 IDR profile over the height resulted from different LPs along with the mean value of the NTHA, inter-story ductility demand of 2, 3, 4 and 5 

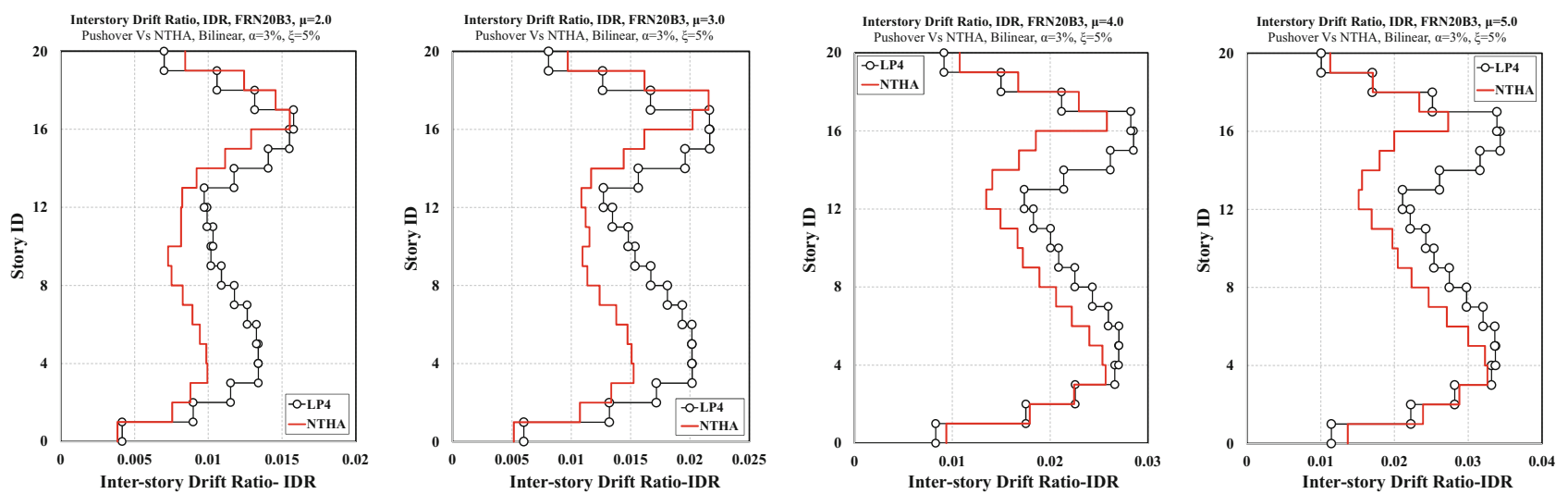

Fig. 8 Inter-story drift angle distribution over the height for the LP4 (MMC) along with the mean value of NTHA in 20-story model, inter-story ductility demand of 2,3,4 and 5
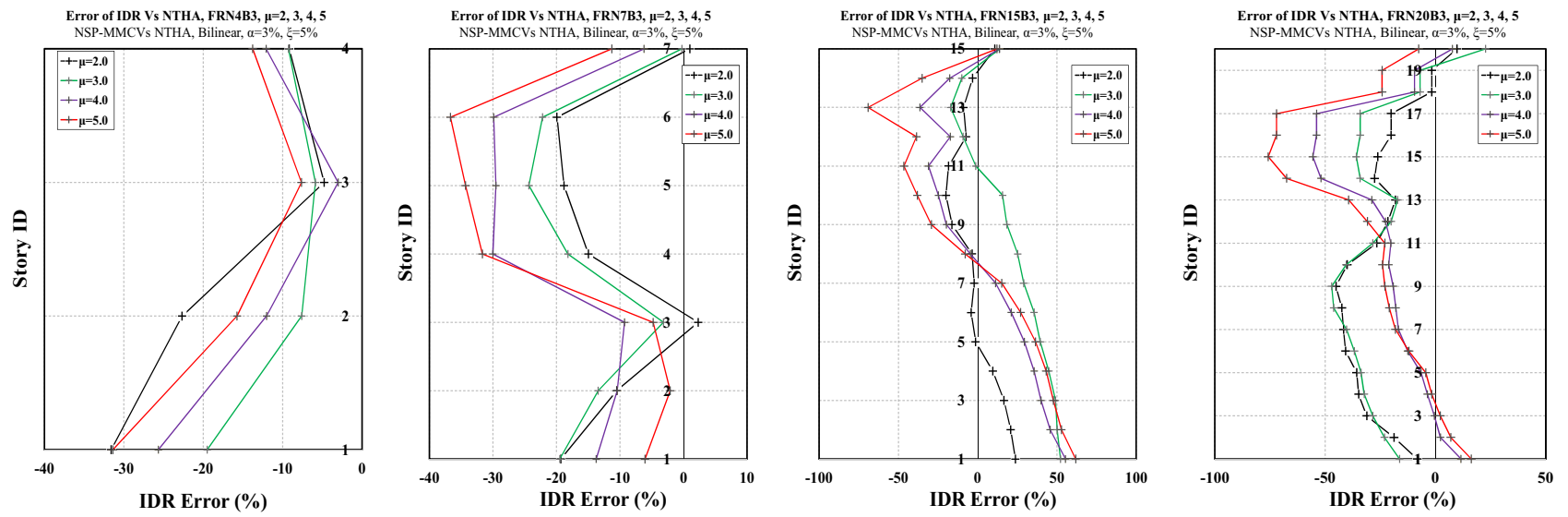

Fig. 9 IDR error profile using NSP-LP4 and NTHA-mean value for different levels of inter-story ductility

stories. This may be interpreted as the effect of higher modes on peak deformation demands.

\section{Global ductility}

By developing pushover methods and tendency of seismic codes to use ductile structures, the ductility concept (demand and capacity) is defined in different performance levels. Initial classification shows that there are three types of ductility which are the global, inter-story and element ductility. To calculate the global ductility, the yield displacement of structure is a key factor. This displacement is derived from the result of pushover analysis using different LPs. Therefore, it seems that the global ductility strongly depends on the LPs. Global ductility $\left(\mu_{\mathrm{g}}\right)$ is the ratio of maximum roof displacement used in NSPs (the target displacement) or peak roof displacement resulted by NTHA to the roofs yield displacement.

$\mu_{\mathrm{g}}=\frac{\Delta_{\max }}{\Delta_{y}}$
It is important to mention that the global ductility resulted from NSPs corresponding to a predefined performance level is called capacity ductility. On the contrary, the ductility calculated by NTHA is called demand ductility.

Following, the $\mu_{\mathrm{g}}$ corresponding to different values of inter-story ductility is calculated and depicted in Fig. 10. In this figure, the red line is the demand global ductility that is obtained from NTHA at the target displacement corresponding to selected inter-story ductility.

Evaluation of Fig. 10 indicates that the inter-story target ductility is higher than the global ductility. This difference is more noticeable by increasing the coefficient of interstory ductility and the period of vibration. Also, for a given period, increasing inter-story ductility increases the global ductility and then it remains constant. However, increasing the period reduces the global ductility ratio. For the structure with long period, global ductility is not affected by period change. Comparing global ductility resulted from different LPs with the result of NTHA indicates that for inter-story ductility of 2 and 3, the global ductility of 

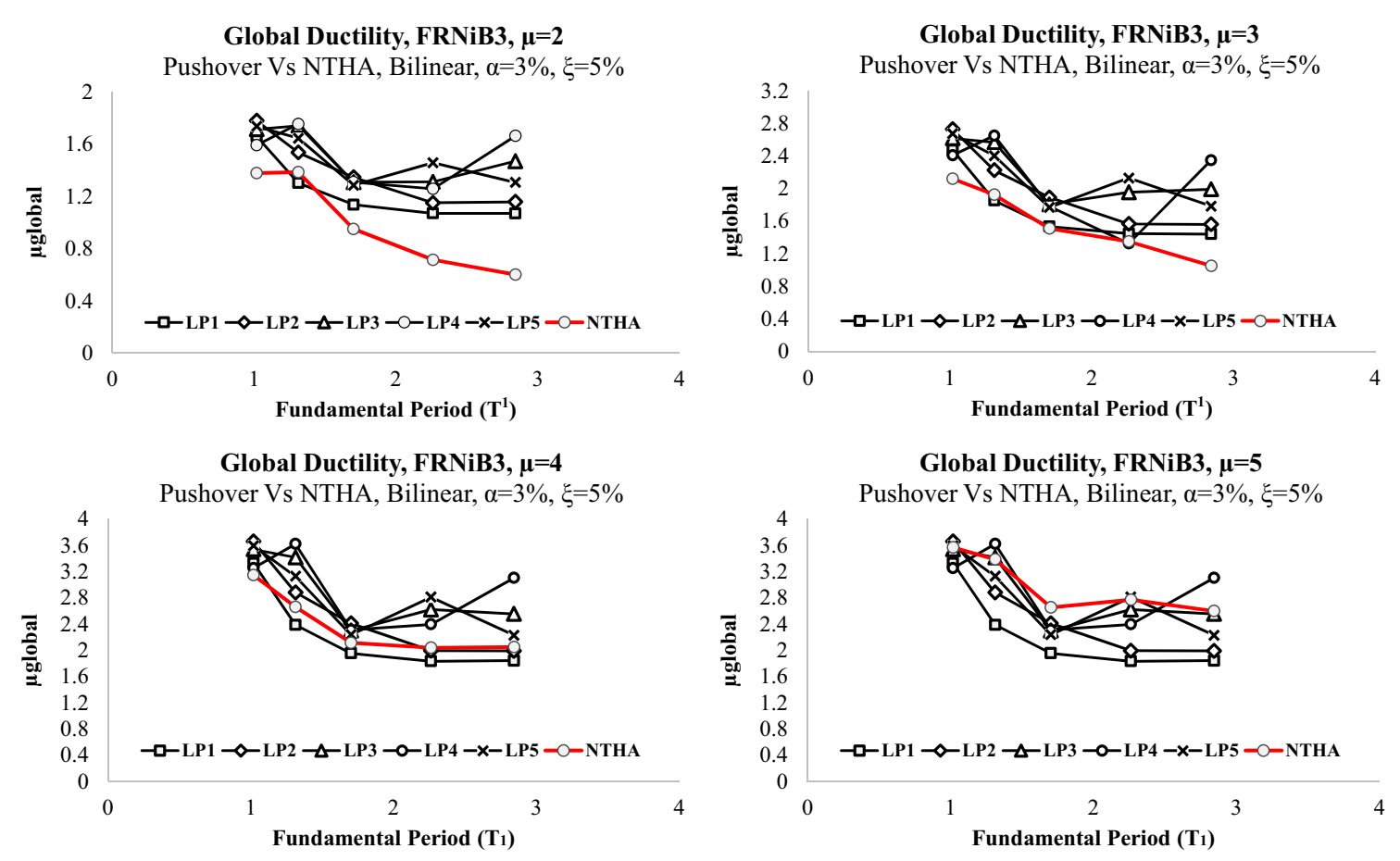

Fig. 10 The variation of global ductility against period resulted from different LPs comparing with the NTHA mean value

pushover method is higher than the NTHA. Increasing the interstory ductility causes that the global ductility obtained by the NTHA is estimated higher than the values resulted from different LPs. In this case, the LP5 (UBPA method) predicts reasonable values for global ductility. In addition, the minimum value of $\mu_{\mathrm{g}}$ relates to the LP1 (uniform load distribution).

\section{Inter-story ductility}

The story ductility demand, defined as the mean value of maximum IDR from NTHA normalized by interstory yield from NSP, i.e., $\mu_{\mathrm{s}}=\delta_{\max } / \delta_{\mathrm{y}}$, is used as the engineering demand parameter in the present paper. The yield interstorey drift ratio was calculated by employing the formula presented in (Gupta and Krawinkler 1999). It should be noted that in the present study, inter-story ductility is limited to the values of 2,3,4 and 5 (defined as a target $\mu_{\mathrm{s}}$ ). Thus, the purpose of this section is to evaluate how much different LPs can estimate correctly the trend and position of critical story (the story, including ductility equal to target ductility) in comparison with the result of the NTHA. Figure 11 indicates the results corresponding to four $\mu_{\mathrm{s}}$ levels for the considered inelastic structures. The results show that in low-rise structure, i.e., 4-story model, different LPs can predict the position of a critical story corresponding to the story in which the target $\mu_{\mathrm{s}}$ locates. The maximum $\mu_{\mathrm{s}}$ demand migrates to the bottom story as the strength decreases ( $\mu_{\mathrm{s}}$ increases) and as the building becomes taller due to the effect of P-Delta. It means that increasing inelastic behavior intensify the second deformation phenomena known as P-Delta. Therefore, all LPs can calculate the critical story more accurately. The worst result belongs to the LP1. It seems that the LP4 (MMC) gives the best estimation of inter-story ductility trend over the height. This capability does not depend on the ductility ratio.

In general the relative increment of the structure height tends to decrease the accuracy of the LPs which don not consider the effect of higher modes. Therefore, due to the participation of higher modes in ultimate response especially at top stories, the estimated inter-story ductility are often lower than the NTHA result. As an example, in the 15-story structure, the LP1 and LP2 could not provide a correct estimation for $\mu_{\mathrm{s}}$ in upper stories. In lower stories, for small value of ductility demand (2 and 3), except LP3 and LP4, other LPs have resulted higher values than the NTHA. This is while in upper stories, the results obtained from different LPs except LP4 (MMC method) are generally lower than the NTHA. By increasing $\mu_{\mathrm{s}}$ in the 15-story structure, it seems that the effect of higher modes is reduced since the peak $\mu_{\mathrm{s}}$ migrates from top to bottom story due to the P- $\Delta$ effect. Therefore, all LPs corresponding to first mode load distribution can estimate the $\mu_{\mathrm{s}}$ accurately. Meanwhile, the LP1, LP2, and LP5 have provided the best estimation in terms of value and position of critical stories. All results obtained from the 15 -story model can also be extended to the 20 -story structure. 

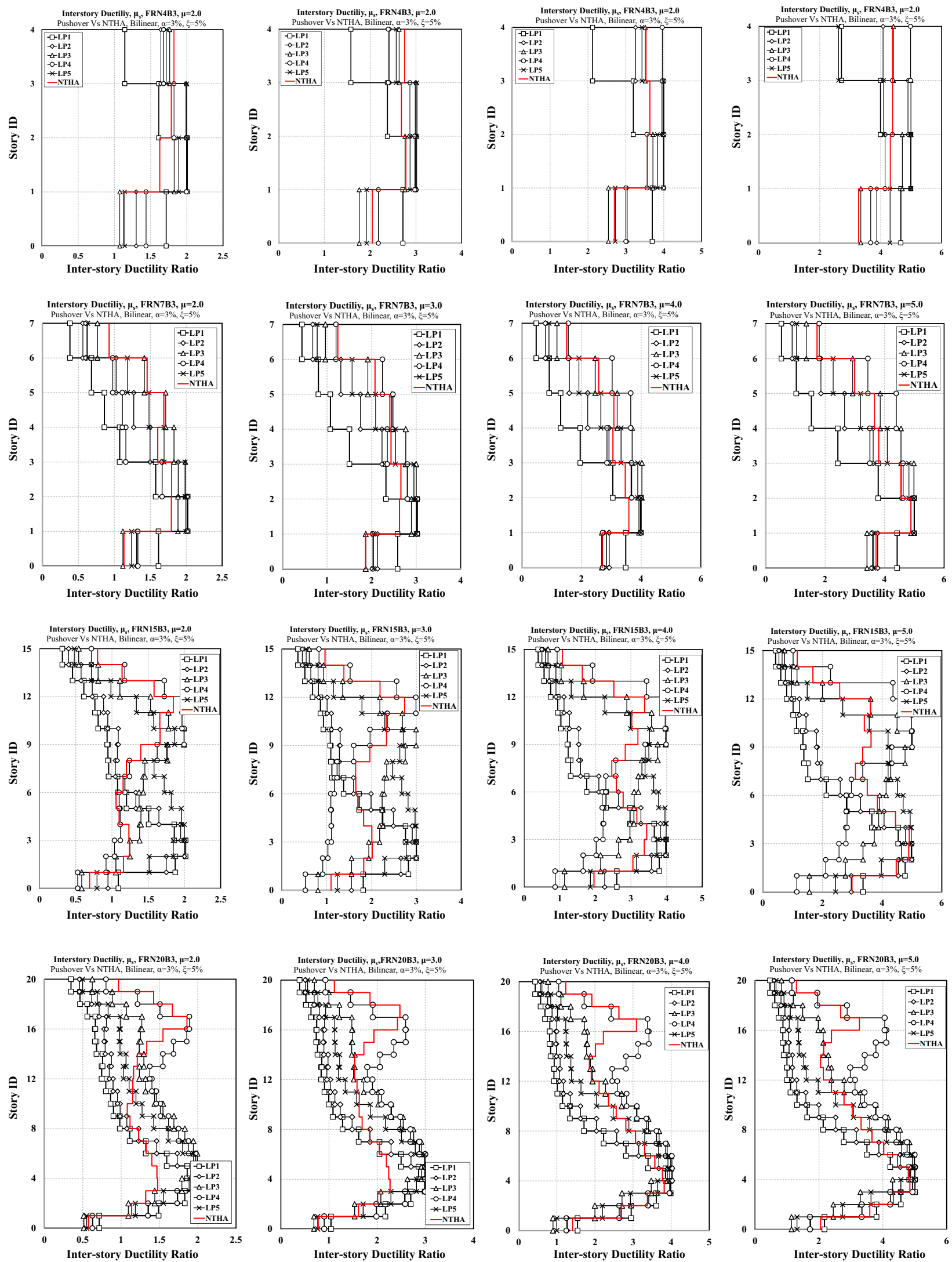

Fig. 11 The $\mu_{\mathrm{s}}$ distribution over the height for different LPs along with NSP, inter-story ductility demands of 2, 3, 4 and 5 

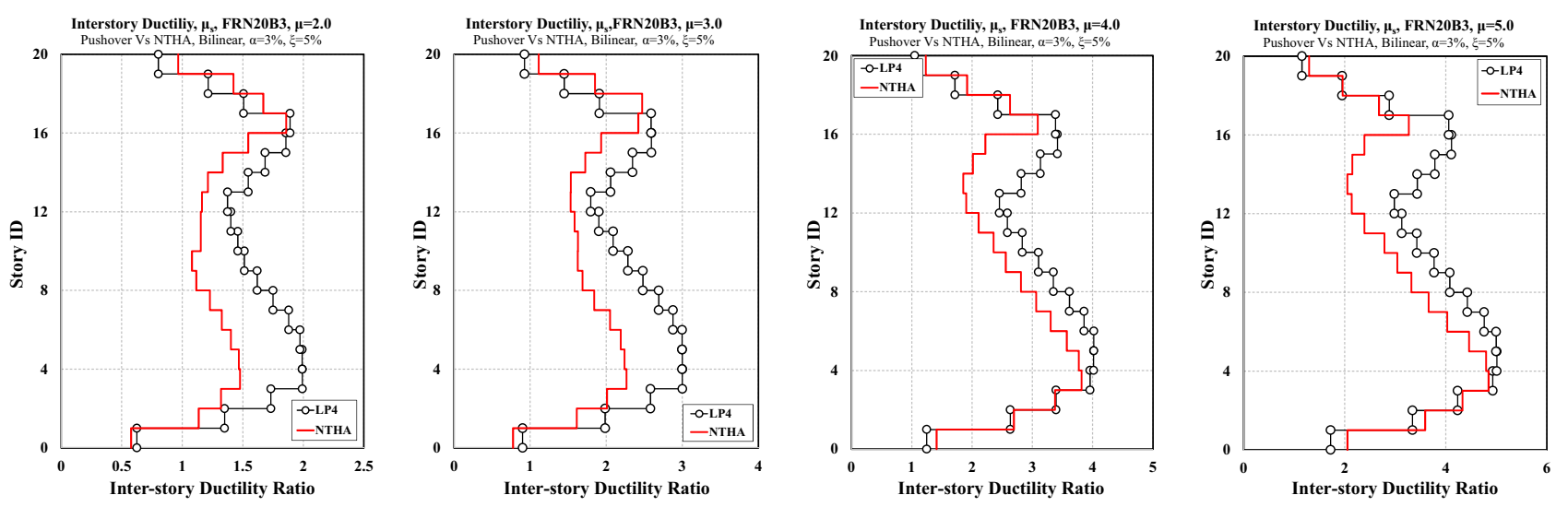

Fig. 12 The $\mu_{\mathrm{s}}$ distribution over the height for the LP4 along with NTHA in 20-story model, inter-story ductility demands of 2, 3, 4 and 5
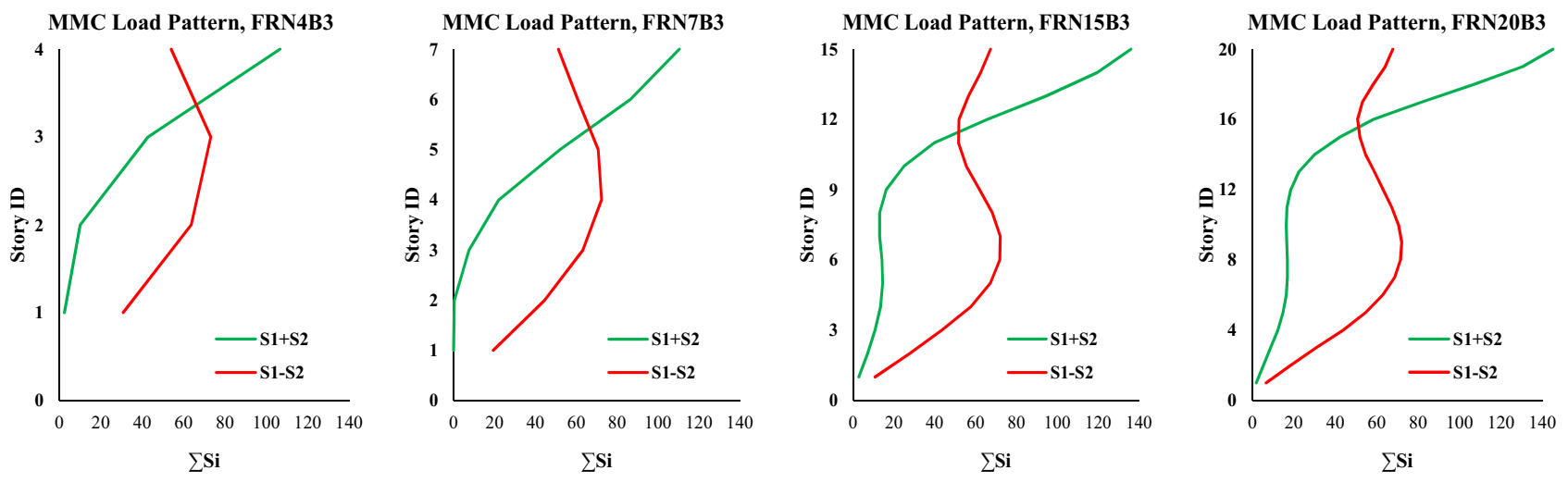

Fig. 13 Two combined modal linear load patterns used in the NSP-MMC

Since, the previously mentioned results show that the LP4 (MMC) can provide an appropriate estimation of interstory ductility demands in high-rise frames, in Fig. 12 the $\mu_{\mathrm{s}}$ resulted from LP4 is compared with values obtained from NTHA for different levels of target ductility. Evaluating the mentioned figure demonstrates that this LP could estimate the trend of $\mu_{\mathrm{s}}$ profile over the height and the position of critical stories (the story corresponding to the maximum $\mu_{\mathrm{s}}$ ) with acceptable accuracy. This issue is confirmed for ductility of 4 and 5 more than before.

\section{Capacity curve of structure}

One of important curves resulting from pushover method is the capacity curve, which generally shows the displacement of control node (roof center of mass) equal to each step of incremental loading. Via this curve, the elastic stiffness of model, post-yield slope of structure, global yield displacement, global ductility, the first plastic hinge formation point and overstrength factor are being calculated. This curve directly depends on the LPs. Reviewing the results of previous sections indicates that using the
MMC load pattern (LP4) can provide a reasonable estimation of inelastic demands of frames with rigid connections under the effect of higher modes contribution. Since in the present article two LPs are considered for MMC method, so, capacity curves of each structure corresponding to a certain inter-story ductility level are calculated. It should be noted that what is provided as the capacity curve of each structure is only for two ductility levels of 2 and 5 . The reason of choosing these two ductility levels is to avoid prolonging the result of this section. Following, two different patterns of MMC method which is provided via Eq. 1, will be re-written here. For better understanding, these two LPs with $S_{1}+S_{2}$ and $S_{1}-S_{2}$ related to the 15-story structure are provided in Fig. 13.

$F_{j}=\alpha_{1} \Gamma_{1} m \phi_{1} S_{a}\left(\xi_{1}, T_{1}\right)+\alpha_{2} \Gamma_{2} m \phi_{2} S_{a}\left(\xi_{2}, T_{2}\right)$

$F_{j}=\alpha_{1} \Gamma_{1} m \phi_{1} S_{a}\left(\xi_{1}, T_{1}\right)-\alpha_{2} \Gamma_{2} m \phi_{2} S_{a}\left(\xi_{2}, T_{2}\right)$

The capacity curves of models are portrayed in Fig. 14. Investigating Fig. 14 indicates that two load patterns used in MMC have led to different capacity curves. Except the 15 -story structure, in other models, the elastic stiffness of the load pattern of the Eq. 9 is higher than the value 
Pushover Capaciy Curve, FRN4B3, $\boldsymbol{\mu}=\mathbf{2 . 0}$

MMC Load Pattern (+ and -), Bilinear, $\alpha=3 \%$

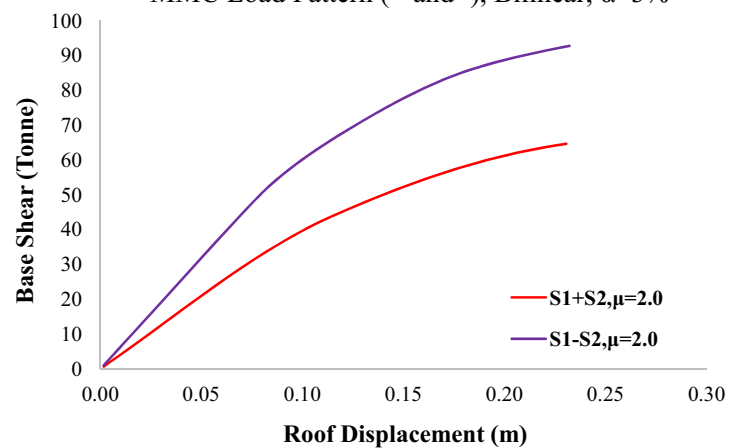

Pushover Capaciy Curve, FRN7B3, $\boldsymbol{\mu}=\mathbf{2 . 0}$

MMC Load Pattern (+ and -), Bilinear, $\alpha=3 \%$

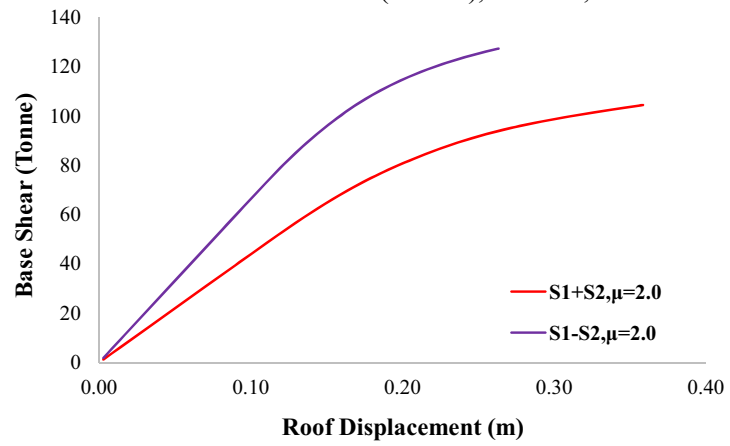

Pushover Capaciy Curve, FRN15B3, $\boldsymbol{\mu}=\mathbf{2 . 0}$

MMC Load Pattern (+ and -), Bilinear, $\alpha=3 \%$

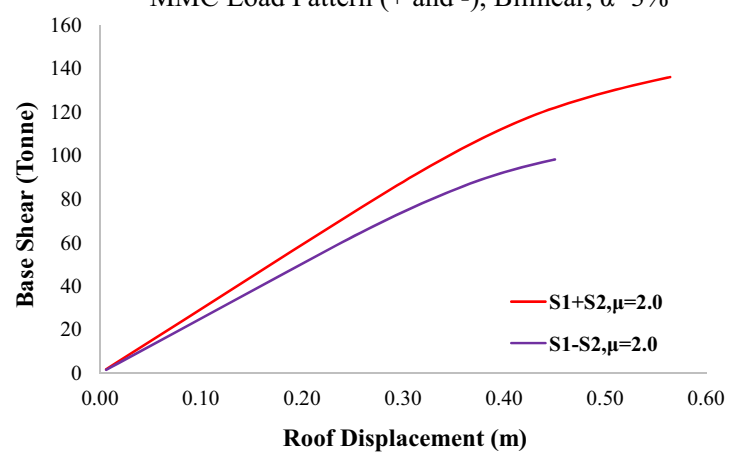

Pushover Capaciy Curve, FRN20B3, $\boldsymbol{\mu}=\mathbf{2 . 0}$

MMC Load Pattern (+ and -), Bilinear, $\alpha=3 \%$

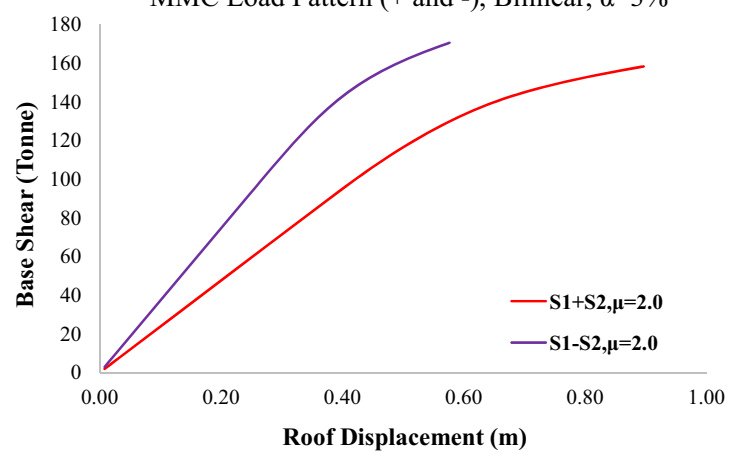

Pushover Capaciy Curve, FRN4B3, $\mu=5.0$

MMC Load Pattern (+ and -), Bilinear, $\alpha=3 \%$

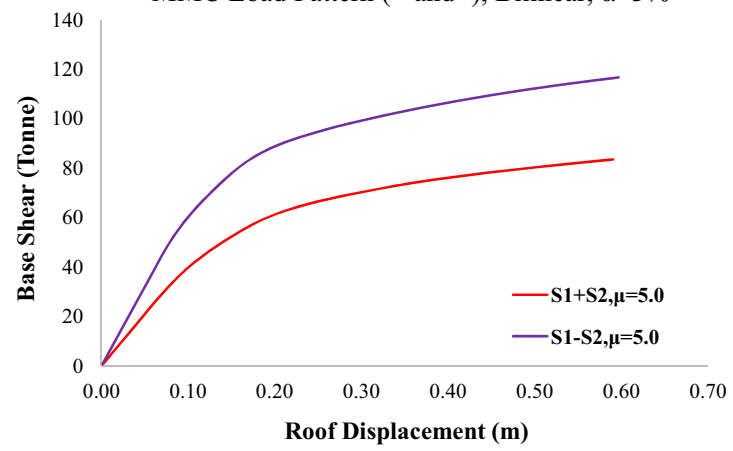

Pushover Capaciy Curve, FRN7B3, $\boldsymbol{\mu}=\mathbf{5 . 0}$

MMC Load Pattern (+ and -), Bilinear, $\alpha=3 \%$

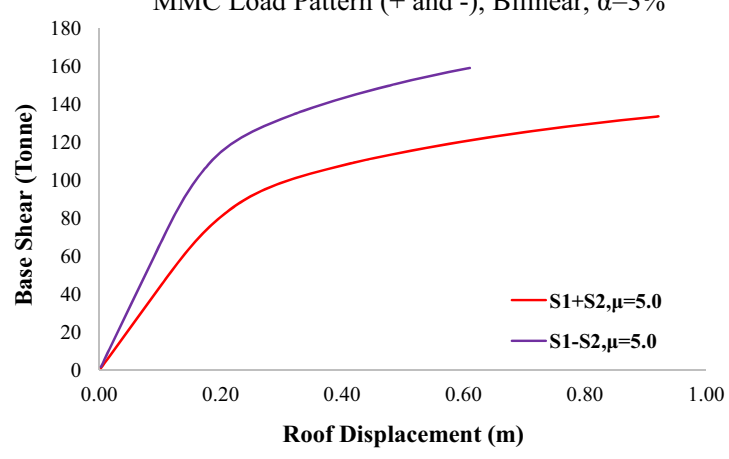

Pushover Capaciy Curve, FRN15B3, $\boldsymbol{\mu}=\mathbf{5 . 0}$

MMC Load Pattern (+ and -), Bilinear, $\alpha=3 \%$

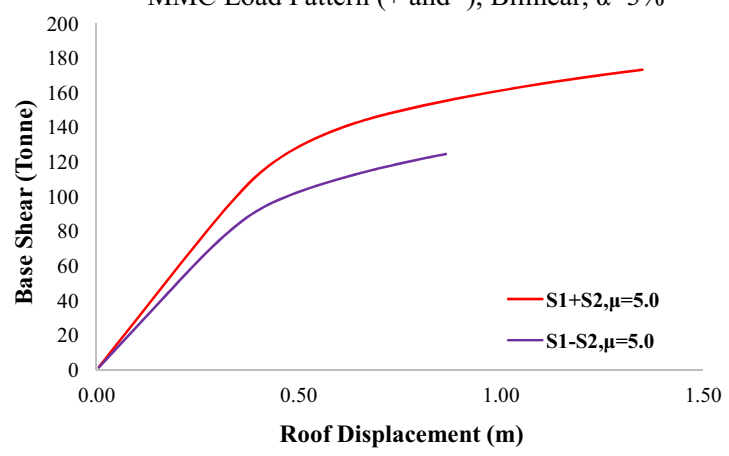

Pushover Capaciy Curve, FRN20B3, $\boldsymbol{\mu}=\mathbf{5 . 0}$

MMC Load Pattern (+ and -), Bilinear, $\alpha=3 \%$

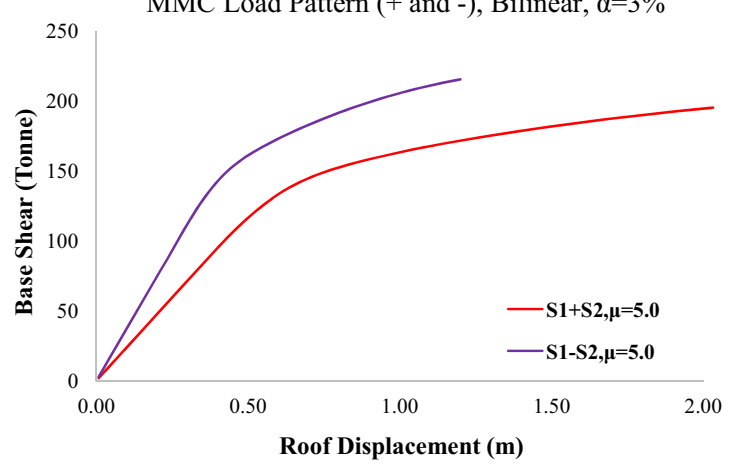

Fig. 14 The capacity curve of structure for two different load patterns of NSP-MMC method, inter-story ductility of 2 and 5 
resulted from the Eq. 8. Whereas, by increasing the structure height, the value of target displacement resulted from $S_{1}-S_{2}$ load pattern is smaller than $S_{1}-S_{2}$ load pattern. In addition, increasing ductility ratio increases the differences between target displacements of two aforementioned LPs.

\section{Results}

By increasing the popularity of Nonlinear Static Procedures (NSPs), it is necessary to evaluate the validity of elastic lateral load patterns (generally based on the first mode of vibration) used to estimate the nonlinear demands. To the best of the authors' knowledge, less attention has been paid to the capability assessment of the relevant load pattern proposed to capture the inelastic demands of structure subjected to the pulse-like near-fault earthquakes. However, expanding and improving a load pattern in which it can estimate the inelastic demand distribution of models over the height (including total drift, inter-story, and component ultimate rotations) but yet retaining the simplicity of invariant distributions, is the subject of recent researches. Hence, in the present paper, in addition to apply five conventional and modified load patterns, nonlinear demands of 2D regular frames are calculated and compared with the values resulting from Nonlinear Time History Analysis (NTHA). This comparison is provided with the definitions of target inter-story ductility for both NDPs and NTHA. The focus of this study is not directly related to the assessment of design requirements rather it is an assessment of evaluation methods used to estimate seismic demands that play a major role in the design process.

This study indicates that for structures responding primarily in the first mode, pushover methods may be a reliable choice to estimate inelastic demands. However, the validity depends on the level of expected inelastic behavior and the number of stories. On the other hand, the results show that in low-rise structures, all load patterns provide fairly accurate estimation of the global and interstory demands. By increasing the number of stories the MMC appears to be promising in terms of better estimating peak values of critical inelastic response quantities such as inter-story drifts. It is shown that considering sufficient number of modes, inter-story drifts estimated by MMC is generally similar to trends resulted from NTHA. Moreover, studying all results shows that due to the pulse like near-fault ground shakings, the MMC method could be used as an appropriate load pattern in calculating distributed inelastic demands of structure over the height. However, the accuracy of this load pattern is dependent on the inter-story ductility level. Finally, this paper indicates that special care should be taken when using pushover procedures since the lateral load pattern used to estimate demand could have a significant influence on the computed demands (each load pattern has an inherent capability to estimate specific response). The comparison of the NTHA and NSPs results reveals that the pushover methods tend to underestimate demands at the upper levels, signifying the relevance of higher mode effects in mid to high-rise structures except the result of MMC. Moreover, each load pattern has a different result of capacity curve with different elastic and inelastic stiffness. Therefore, using the MMC cannot guaranty the unique ultimate capacity curve of the structure and this is the main disadvantage of this method.

Open Access This article is distributed under the terms of the Creative Commons Attribution 4.0 International License (http://crea tivecommons.org/licenses/by/4.0/), which permits unrestricted use, distribution, and reproduction in any medium, provided you give appropriate credit to the original author(s) and the source, provide a link to the Creative Commons license, and indicate if changes were made.

\section{References}

ANSI/AISC 360-10 (2010) Specification for structural steel buildings. American Institute of Steel Construction, INC, Chicago, Illinois 60601-1802

Applied Technology Council A (1996) Seismic evaluation and retrofit of concrete buildings. Applied Technology Council, report ATC40. Redwood City

ASCE/SEI 41-13, A. S. (2013) Seismic evaluation and retrofit of existing buildings. 1801 Alexander Bell Drive American Society of Civil Engineers

Aydinoğlu MN (2003) An incremental response spectrum analysis procedure based on inelastic spectral displacements for multimode seismic performance evaluation. Bull Earthq Eng $1(1): 3-36$

Baker J (2007) Quantitative classification of near-field ground motion using wavelet analysis. Bull Seismol Soc Am 97(5):1486-1501

Chopra AK, Goel RK (2002) A modal pushover analysis procedure for estimating seismic demands for buildings. Earthq Eng Struct Dynam 31(3):561-582

Chopra AK, Goel RK, Chinatanapakdee C (2004) Evaluation of a modified MPA procedure assuming higher modes as elastic to estimate seismic demands. Earthq Spectra 20(3):757-778

Gerami M, Abdollahzadeh D (2015) Vulnerability of steel momentresisting frames under effects of forward directivity. Struct Design Tall Spec Build 24(2):97-122

Gupta A, Krawinkler H (1999) Seismic demands for the performance evaluation of steel moment resisting frame structures. Stanford University

Gupta B, Kunnath SK (2000) Adaptive spectra-based pushover procedure for seismic evaluation of structures. Earthq Spectra 16(2):367-392

Computers and Structures, Inc., ETABS 2013—extended 3D analysis of building systems, nonlinear. Berkeley, California 94704, USA

Iran's Building and House Research Center (2014) Iranian code of practical deign of buildings against earthquake (Standard No.2800). BHRC Publications, Tehran 
Iranian National Building Regulations (2008) Loads on buildings (Code No.6), Iran National Building Regulations Center. INBR Publications, Tehran

Jan TS, Liu MW, Kao YC (2004) An upper-bound pushover analysis procedure for estimating seismic demands of high-rise buildings. Eng Struct 2004(26):117-128

Kalkan E, Kunnath SK (2004) Method of modal combinations for pushover analysis of buildings. In: Proceedings of the 13th world conference on earthquake engineering, paper

Kalkan E, Kunnath SK (2006) Adaptive modal combination procedure for nonlinear static analysis of building structures. J Struct
Eng 132(11):1721-1731. doi:10.1061/(ASCE)0733-9445(2006) $132: 11(1721)$

Kramer SL (1996) Geotechnical Earthquake Engineering. Prentice Hall, New Jersey

McKenna F, Fenves G, Scott M (2000) Open system for earthquake engineering simulation. University of California, Berkeley

Moghadam A, Tso W (2002) A pushover procedure for tall buildings. In: Proceedings of the Twelfth European Conference on Earthquake Engineering, London, United Kingdom, paper 